\title{
Palabras cruzadas en torno a Soleada
}

\author{
Soleada | Gabriela Trettel | 2016 \\ Carolina Córdoba* \\ Escuela de la Orientación Lacaniana
}

Recibido: 8 de mayo 2017; aceptado: 12 de junio 2017

\begin{abstract}
Resumen
Este artículo cruza las palabras en torno a Soleada (Trettel, 2016), un film que capta a través de la sutil y arriesgada mirada de su directora, la intimidad de una mujer de mediana edad. La protagonista instalada en un intervalo determinado de la vida, en el momento que nada le falta, se confronta con la emergencia del afecto lacaniano prínceps, afecto que no engaña: la angustia. Una mujer no toda madre, acontece. La soledad como medio conduce a la protagonista en algunos momentos a la angustia, lo femenino a esa zona de soledad radical que habita en el goce del Otro.
\end{abstract}

Palabras clave: Mujer | Madre | Angustia | Goce femenino | Soledad radical | Extravío

Crosswords about Soleada

Abstract

This article crosses words around Soleada (Trettel, 2016), a film that captures through the daring and subtle eyes of its Director the intimacy of a middle-aged woman. The protagonist installed in an interval of her life, at the time that nothing is missing, is confronted with the emergence of the Lacanian affection princeps, affection that doesn't deceive: the anguish. One woman not every mother, happens. Loneliness as a way leads to the protagonist in some moments to the anguish, the femenine to that area of radical loneliness that lives in the Other jouissance.

Keywords: Woman | Mother | Anguish | Female jouissance | Radical Loneliness | Loss

\section{Decir algo serio sobre qué quiere una mujer}

Cinco letras, vertical, comienza con la letra " $m$ ". Dícese de la respuesta de Freud ante el enigma que se le impuso: “¿qué quiere una mujer?” La respuesta freudiana a qué quiere una mujer es...: ser Madre (Freud, 1931). Como el número de los casilleros coincide, alguien se esfuerza en escribir Mujer de un modo indeleble. Pero la tinta se torna invisible, el papel se vuelve incorpóreo, las letras se salen del casillero y se escriben contingentemente en un zigzag tornasolado que no respeta ningún plano horizontal ni vertical. Es que la mujer no existe como universal, como un todo, “existe una por una y no-toda” (Lacan, 1971-72, p. 101).

Lacan en el Seminario 20 en relación a la mujer-no existe enseña: "Se le llama impropiamente la mujer, ya que como señalé la vez pasada, el la de la mujer, a partir del momento en que se anuncia con un no-todo, no puede escribirse" (Lacan, 1972-73, p. 98).

He de destacar la sutileza de la mirada de la directora de esta película, Gabriela Trettel. Ella capta en algunos planos la suspensión en los gestos, los divinos detalles a través de una cámara que se propuso cautivar puntillosamente la delicada intimidad de la protagonista, en la actuación de Laura Ortiz. Soleada, film cordobés del 2016, logra hacer legible las letras tornasoladas y bajo relieve de un crucigrama, un pasatiempo, que escribe una mujer, una no-toda madre, que estalla como el vidrio de la mesa del living, de esa casa de verano.

Una verdadera mujer acontece allí, y en esa contingencia se produce esa revelación del goce femenino, que la distancia de toda-madre.

En el inédito Seminario 14, La Lógica del fantasma, más precisamente en la clase 10 de mayo del 1967, Jacques Lacan se queja de que los psicoanalistas no digan nada sobre el goce femenino. No obstante, de la mujer en tanto madre, hablamos sin parar.

Y unos días más adelante agregará: "en esta cuestión de la sexualidad femenina no se ha hecho jamás un paso 
que sea serio, viniendo de un sujeto aparentemente definido como macho por su constitución anatómica. Pero lo más curioso es que las psicoanalistas mujeres, aproximándose a este tema muestran todos los signos de un desfallecimiento que sugieren que están, por lo que podrían tener que formular, aterradas de suerte a que la cuestión del goce femenino no parece próxima a ser puesta en estudio ya que ¡mi Dios! es el único lugar donde se podría decir algo serio" (Lacan, clase del 24/05/1967, inédito).

\section{La angustia lacaniana}

"Soleada" es una palabra cuasi anagramática con "soledad" salvo por la letra "a" que se agrega para soleada y la letra "d" que le falta para ser soledad.

$\mathrm{La}$ "a” es la letra inicial y terminal del nombre de la protagonista - Adriana - una mujer de 40 años. Adriana que al parecer lo tiene todo en tanto madre, hijos, marido, casa de veraneo, se angustia. El film consigue transmitir sobre el afecto prínceps que el psicoanálisis lacaniano enseña. ¿Qué falta cuando nada falta?

Sucede que la "a" es la letra de la palabra angustia. Y también Lacan llamó "a” al objeto resto imposible de significantizar, que la angustia permite localizar. Jacques Lacan dice "cuando la falta viene a faltar" (Lacan, 1962-63, p. 52), emerge la angustia. Cuando la falta se tapona con el objeto plus de gozar y no se preserva ese lugar vacío para que surja el deseo como causa, aparece la angustia.

La angustia es "pre-sentimiento" (Lacan, 1962-63, p. 87), afecto que no engaña, de algo que parece estar irrumpiendo. El fin de un modo de vida, que se recubre con ciertas formas del desamor, cierto tedio, hastío que anuncian una separación, atisbos de un desacople y una distancia que se vuelve intolerable y se hace evidente. Porque en la ausencia física del partenaire, y en el cambio de hábitat de la casa de verano, en ese intervalo que se produce, se hace presente esa soledad como medio. Esta última toma la modalidad de angustia productiva que procura recuperar ese vacío - medio actuante-, para relanzar el deseo nuevamente. ¿Con el mismo partenaire, con el otro? No sabemos. Lo que sí podemos presagiar es que Adriana no será la misma.

\section{Capturar lo ominoso}

El film captura magistralmente esos momentos de esa vacilación subjetiva, de irrupción y perturbación en los ruidos de la noche, y lo sonoro de la propia respiración, que se suspende y estremece en el sosiego de la calma, del cuerpo extendido que flota en el remanso del río. "Ruidos tan íntimos que retumban afuera" (Ordoñez, 2016, s/p) como tan bien lo ha enunciado Pilar Ordoñez. Lo éxtimo, lo ominoso, lo Unheimlichkeit, que sucede cuando lo familiar y doméstico transmuta en extranjero.

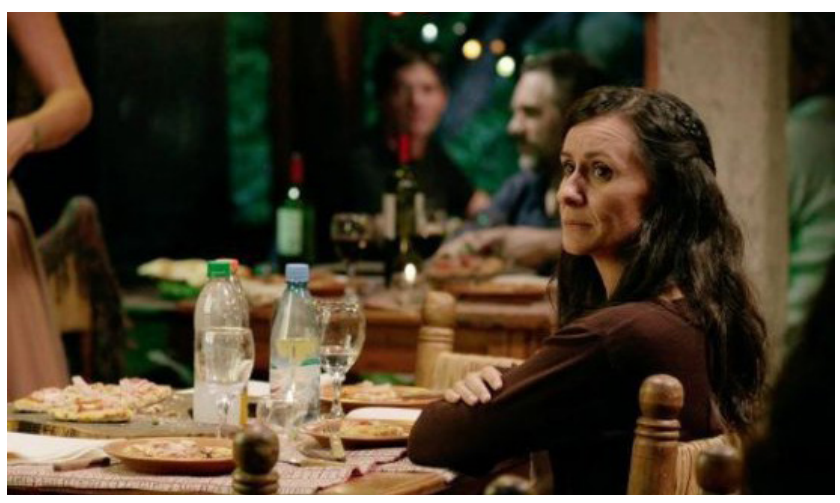

\section{Aquiles no alcanza a la tortuga}

Adriana atraviesa un tramo de su vida que hace presente resquicios y fisuras. $\mathrm{Y}$ allí en esos intersticios, los bordes de lo femenino se insinúan en un cuerpo nuevo y extraño que acusa el devenir de lo real del tiempo, con las varias canas que ella no se ve, no se quiere ver y que su hija se las señala sin tapujos. Como lo es también sin disimulo, el ineluctable paso del tiempo, la iniciación de la vida sexual de los hijos que la requieren de un modo instrumental. Mamá es un GPS de la ubicación de los objetos domésticos y al mismo tiempo ya no la necesitan como en la infancia. Un marido que la deja por el trabajo en el tiempo de las vacaciones. Desde el inicio ella se despierta, ante una maniobra torpe de él que, apurado, pasa a otro auto y ante la pregunta "¿qué pasó?", él le dice: "un boludo que se cruzó", y ella le advierte “entonces anda más despacio". Él en tanto Aquiles, no alcanza a la tortuga. Y ella no se vuelve a dormir en el sueño de lo ya obtenido. Hay luego la contingencia de un encuentro con una mirada de quien se le cruza en un momento sin palabras, o los balbuceos de una seducción ante una mujer niña. Él la mira mirar. Ella ríe y se vivifica.

\section{Extravío}

Soleada comparte con soledad la letra “e”. Extravío de lo femenino. ¿Por dónde anduvieron esas dos mujeres, 
circunstancialmente madre e hija, durante varias horas para no llegar al río? ¿Por qué espacio transfinito de palabras o silencios el tiempo se les pasó para no llegar a destino? Nada pueden decir, por cual insondable zona, se perdieron ambas, que en compañía habitaron un espacio de soledad radical.

\section{Lo femenino: entre centro y ausencia}

Lo femenino agujerea el todo-madre y entonces abre un espacio que ya no podría funcionar desde la lógica presencia-ausencia que delimita una temporalidad y un intervalo medible. Ni tampoco desde las coordenadas espaciales del centro y la periferia. Entre centro y ausencia, lo femenino viene a insinuar aquello que no haría falta que existiera, ese punto invisible que sitúa, siempre malogradamente, la alteridad radical que define al goce del Otro. Por eso mismo suele ser segregado como extraño y extranjero. Ese "entre" da lugar a un espacio imposible de recorrer. Lo femenino que hace estallar, hoy más que nunca, el imperio de la cifra y la exactitud que comanda el discurso de la ciencia desencadenada con el delirio de que todo puede ser evaluado. Esta película muestra en el estallido de lo frágil, cómo la mujer como acontecimiento, da cuenta de la deslocalización estructural del goce femenino, lo cual lo torna imprevisto, e imponderable (Bassols, 2017).

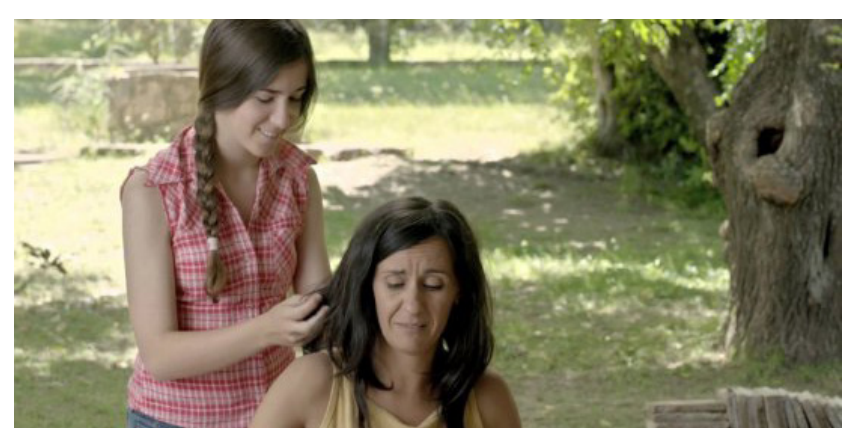

\section{La apuesta femenina más allá del provincianismo}

Soleada tiene la letra "l" de local. Las locaciones en las Sierras Chicas, ese río, esa olla que estando próxima se vuelve lejana y deliciosa, nadie sabe dónde queda y es probable que muchos la conozcamos pero es desde la película que a todos nos gustaría ir. Localizar la tonada, lo propio, en mi opinión, no afecta a esta película de altanería localista y entonces tampoco rinde culto al provincianismo. El provincianismo portugués según Fernando Pessoa, surge en el empalme de las siguientes coordenadas: el desprecio a lo local y la admiración a lo extranjero, y así los provincianos se defienden posicionándose con un localismo infatuado (Pessoa, 2005). Considero que Soleada subvierte esa posición y perturba esa defensa. Soleada es una apuesta que en tanto femenina se arriesga a que la joven comunidad de amantes del cine hecho en Córdoba por cordobeses, la más cercana, se inscriba topológicamente en lo más lejano, indagando ese continente negro, terra incógnita de lo femenino que atraviesa y desborda las fronteras, tornando así lo más foráneo, lo más extranjero, en algo próximo.

\section{Otra para ella misma}

La "d" del final de la palabra soledad es la "d" que falta en Soleada para que no sea del todo anagramática con soledad. Pero allí en esa "d" que falta, se lee el deseo, porque Soleada lo ilumina paradójicamente cuando la luz de la cámara se apaga. La chance para que la vida de Adriana recomience cuando la película termina, esa apertura a lo posible de que tanto una película como una mujer sea Otra para otro, pero fundamentalmente Otra para ella misma.

\section{Referencias}

Bassols, M. (2017). Lo femenino entre centro y ausencia. Buenos Aires: Grama.

Freud, S. (1931 [1979]). “Sobre la sexualidad femenina” en Obras completas. Volumen 21. Buenos Aires: Amorrortu.

Lacan, J. (1962-63 [2010]). “La Angustia” en El Seminario de Jacques Lacan. Libro 10. Buenos Aires: Paidós.

Lacan, J. (1971-72 [2012]). “...o peor” en El seminario de Jacques Lacan. Libro 19: ... O peor. Buenos Aires: Paidós.

Lacan, J. (1972-73 [1981]). “Aún” en El Seminario de Jacques Lacan. Libro 20. Buenos Aires: Paidós.

Lacan, J. (1967) “La Lógica del fantasma”. Seminario 14. Inédito.

Ordoñez, P. En Revista Psine. http://revistapsine.com.

Pessoa, F. “El provincianismo portugués”. Revista Ñ Clarín. 25 de noviembre del 2005. 